\title{
Patogenesia do óleo essencial e homeopatias de Eucalyptus citriodora em plantas de feijão (Phaseolus vulgaris)
}

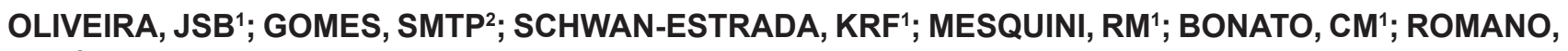 \\ EDB $^{2}$ \\ ${ }^{1}$ Universidade Estadual de Maringá (UEM), Departamento de Agronomia, Av. Colombo, 5790, CEP: 87020-900. \\ ${ }^{2}$ Instituto Agronômico do Paraná (IAPAR) Rodovia Celso Garcia Cid, km 375 - Três Marcos. CEP: 86047-902 - \\ Caixa Postal 481 - Londrina - PR.
}

\begin{abstract}
RESUMO A homeopatia baseia-se no princípio da cura pelos semelhantes, e na experimentação no indivíduo sadio, doses mínimas e medicamento único. O uso de tratamentos a base de soluções dinamizadas aplicadas em vegetais aumentou nas ultimas décadas, sendo assim necessária a experimentação patogenésica para aplicação de todos os princípios homeopáticos e consolidação da Matéria Vegetal Homeopática. O ensaio patogenésico com plantas de feijão tratadas diariamente via pulverização e irrigação utilizando óleo essencial de Eucalyptus citriodora em diluições $(0,5$ e $1 \%)$ e dinamizados $(12$ e $30 \mathrm{CH})$ revelaram sintomas externos semelhantes aos provocados por Pseudocercospora griseola, agente causal da mancha angular em feijoeiro. O estudo patogenésico com E. citriodora levanta a possibilidade deste ser utilizado no controle da mancha angular de acordo com o princípio homeopático da cura pela similitude.
\end{abstract}

Palavras-chave: homeopatia, sintomas patogenésicos, matéria vegetal homeopática, mancha angular.

\begin{abstract}
Pathogenesis of essential oil and homeopathies of Eucalyptus citriodora in bean plants (Phaseolus vulgaris). Homeopathy is based on the principle of cure by similarity and on the prescription of minimal doses and single medicine to healthy individuals. In plants, performing treatments on the basis of drug dynamisation has increased in the recent decades. In these treatments, it is necessary to conduct a pathogenetic experimentation in order to apply homeopathic principles and to consolidate homeopathic plant material. Through a pathogenetic test with bean plants treated daily by pulverization and irrigation, using diluted and dynamized essential oil of Eucalyptus citriodora - (dilutions: 0.5 and $1 \%$ ) (oil dynamisation: 12 and $30 \mathrm{CH}$ ) -, there appeared external symptoms similar to those symptoms caused by Pseudocercospora griseola, i.e., the causal agent of angular leaf spot of bean. The pathogenetics study with $E$. citriodora raises the possibility of its application to control angular leaf spot in bean plants in accordance with the homeopathic principle of cure by similarity.
\end{abstract}

Keywords: Homeopathy; pathogenetics ymptoms; homeopathic plant material, angular leaf spot.

\section{INTRODUÇÃO}

A homeopatia, ciência criada pelo médico Alemão Samuel Hahnemann, tem como princípios básicos a experimentação clinica de substâncias em indivíduos sadios, a cura pelos semelhantes, a administração de doses mínimas e medicamento único. A utilização da homeopatia busca uma abordagem integrativa dos seres vivos e a valorização de sua individualidade. Considerada ciência aplicada, seu uso era direcionado exclusivamente ao homem, mas, nas últimas décadas, passouse a ser utilizada em tratamentos de animais e plantas. Trabalhos realizados por Rossi et al (2007) mostraram que vegetais respondem a estímulos homeopáticos, relatando uma redução de até 35\% da massa fresca de titirica.

Melhoria dos mecanismos de resistência, sementes mais vigorosas, variação na produção de princípios ativos, alteração de padrão energético, maior resistência a doenças e pragas, desintoxicação e aumento da produção são benefícios verificados pelo uso da homeopatia em vegetais (Lippert e col, 2007).

Qualquer substância orgânica ou inorgânica pode ser submetida ao método homeopático de preparação medicamentosa. Porém, teoricamente, tal substância somente deveria ser utilizada 
na prática médica homeopática depois de ter passado pelo método da experimentação em indivíduos sadios, experimentação patogenésica ou experimentação pura, sendo esta a base para a escolha de um medicamento homeopático individualizado (Neto, 2006).

O conjunto de sintomas patogenésicos forma as Matérias Médicas Puras (Zoby, 2003), o que ainda não foi feito para vegetais devido ao número reduzido de experimentações. Devido a isso, o princípio da cura pelos semelhantes acaba muitas vezes sendo ignorado (Bonato, 2007). A experimentação de diferentes substâncias em plantas sadias deve ser feita para a estruturação de bases sólidas e emprego da homeopatia na agricultura, anotando-se todos os sinais e sintomas surgidos buscando relacioná-los com as enfermidades ou desequilíbrios comuns daquela espécie vegetal. As substâncias devem ser testadas nas doses tóxicas, hipotóxicas e dinamizadas, para revelar todos os sintomas.

Observa-se que soluções dinamizadas apresentam capacidade patogenética de despertar sinais e sintomas análogos aos despertados pelas substâncias nas doses não homeopáticas. Garbim et al (2009) avaliaram o efeito de sucessivas aplicações de ácido bórico em doses homeopáticas sobre plantas de feijão e observaram a manifestação de sintomas semelhantes as plantas que foram intoxicadas pela aplicação da dose padrão (não homeopática) na mesma frequência. Como a presença de necroses de cor castanha clara ou escura com desenvolvivento clorose ao seu redor. As pontas das folhas apresentaram necrose, seguida de amarelecimento e queda do folíolo.

O E. citriodora é um vegetal cultivado para fins múltiplos, como a extração de óleo essencial presente em suas folhas, usado como repelentes de insetos, inibidores da germinação e de crescimento de outras plantas, controladores da atividade microbiológica de fungos e bactérias, ativador dos mecanismos de defesa latentes. Neste sentido, o objetivo deste trabalho foi observar e descrever os sintomas patogenésicos provocados pelo óleo essencial e homeopatias do óleo essencial de $E$. Citriodora em feijoeiro.

\section{MATERIAIS E MÉTODOS}

\section{Obtenção do óleo essencial}

Óleo essencial de Eucalyptus citriodora Hook (Myrtaceae), foi cedido pela Universidade Federal da Grande Dourados (UFGD) extraído por meio do processo de hidrodestilação e submetido à análise qualitativa por cromatografia gasosa acoplada à espectrometria de massa (CG/EM). $O$ cromatógrafo utilizado foi o modelo Shimadzu CG17A equipado com detector por ionização de chamas (FID). O equipamento foi operado nas seguintes condições: coluna HP1 (30 m x 0,25 mm) com fase ligada DB5, temperatura do injetor de $220^{\circ} \mathrm{C}$; programação da coluna com temperatura inicial de $40{ }^{\circ} \mathrm{C}$, sendo acrescidos $4{ }^{\circ} \mathrm{C}^{-1}$, até atingir $240^{\circ} \mathrm{C}$; gás carreador hélio ( $1 \mathrm{~mL}$ min-1); taxa de split 1:10 e volume injetado de $1 \mu \mathrm{L}$ (solução em metanol). Os espectros obtidos foram comparados com o banco de dados da biblioteca NIST/05, a quantificação de cada constituinte obtida por meio de normalização de áreas (\%).

\section{Preparo das homeopatias}

Para a preparação dos tratamentos na forma homeopática o óleo essencial de E. citriodora passou por trituração em lactose em escala centesimal Hanemaniana até a terceira dinamização $(3 \mathrm{CH})$. A partir desta dinamização passaram a ser insumo líquido, álcool de cereais $70 \%$ ou $0,3 \%$. No processo farmacotécnico de preparação da dinamização centesimal hahnemanniana $(\mathrm{CH})$, cada passo corresponde à diluição do óleo na concentração 1/100, seguida de 100 agitações vigorosas (sucussões) e o algarismos arábicos correspondem ao número de vezes que o processo foi repetido (FHB, 1997). Foram preparadas dinamizações 12 e $30 \mathrm{CH}$ para ambas as graduações alcoólicas (70 e 0,3\%)

\section{Bioensaios}

O experimento foi conduzido em casa de vegetação no Instituto Agronômico do ParanáIAPAR, Londrina - Paraná. Sementes de feijão (Phaseolus vulgaris) cultivar Carioca foram semeadas em vasos com aproximadamente 2,2 $\mathrm{Kg}$ de substrato, não estéril, preparado com terra de barranco, areia e esterco de curral na proporção 3:1:1 (m:m:m). As aplicações foram realizadas entre os estádios fenológicos V3 e V4. Os tratamentos utilizados foram: Óleo essencial (OE) nas doses $0,5 \%$ e $1 \%$ diluído em água de osmose reversa, e homeopatias do óleo nas dinamizações $12 \mathrm{CH}$ e $30 \mathrm{CH}$ (70 e $0,3 \%$ de álcool) diluidas $1 \%$ em água destilada. Os controles foram álcool 0,7\%, 0,003\% (graduação alcoólica semelhante às dinamizações após diluição) e controle negativo água de osmose reversa. Ambas homeopatias nas duas graduações alcoólicas foram aplicadas tanto via pulverização como por irrigação.

As aplicações foram realizadas diariamente com pulverizador manual tipo SPRAY $-500 \mathrm{~mL}$, até o ponto de escorrimento, nas faces adaxiais e abaxiais em todas as folhas da planta, pelo meio de irrigação as plantas correspondentes receberam $30 \mathrm{~mL}$ dos tratamentos, totalizando 10 aplicações.

Rev. Bras. PI. Med., Campinas, v.15, n.4, supl.I, p.734-741, 2013. 
O delineamento experimental foi inteiramente casualizado com quinze tratamentos e seis repetições. A parcela experimental foi constituída por uma planta por vaso.

As avaliações de fitointoxicação teve início 12 horas após a aplicação dos tratamentos, por meio de descrições dos sintomas conforme metodologia proposta por Carneiro (2004). Quatro dias após o inicio dos tratamentos, a área foliar total $\left(\mathrm{cm}^{2}\right)$ foi determinada pela fórmula $Y=0,02205 . X^{2}$, onde " $X$ " corresponde à largura do folíolo central das folhas de feijão, "Y" corresponde à área do trifólio, e 0,02205 é uma constante calculada para folhas de feijão (Carneiro, 1997) totalizando três avaliações com intervalos de quatro dias. Na última avaliação a altura das plantas foi determinada medindo-se a distância vertical entre a superfície do solo e o último nó da haste principal das plantas.

Os resultados obtidos foram submetidos à análise de variância (ANOVA) com significância a $5 \%$ de probabilidade pelo teste $F$, e quando significativo submetidos ao teste de comparação de médias Scott-Knott (5\% de probabilidade) por meio do programa estatístico SISVAR v.4.2 (Ferreira, 2003).

\section{RESULTADOS E DISCUSSÃO}

Sintomas de fitotoxidade ocasionados pelo óleo essencial de E. citriodora foram observados 24 horas após a aplicação dos tratamentos. Os tratamentos $0,5 \%, 1 \%(\mathrm{OE}), 12 \mathrm{CH}$ e $30 \mathrm{CH}$ com teor alcoólico $0,003 \%$, e 12CH com teor alcoólico $0,7 \%$ aplicados via pulverização apresentaram sintomas de manchas foliares translúcidas de formato irregular e principalmente de formato angular, de tamanho variando entre 3 e $20 \mathrm{~mm}$, tornando-se acinzentadas e em alguns casos castanho, pardas, e com formação de halo avermelhado, tornandose necróticas. Foi observado que as manchas apresentaram-se aleatóriamente entre as nervuras secundárias, em alguns casos concentradas próximos às nervuras centrais (Figura 1). Nas bordas das folhas foi observado a presença de necrose e redução na altura média da planta e área foliar. Os sintomas supracitados não foram constatados nas testemunhas.

Os tratamentos com óleo essencial nas doses não homeopáticas (0,5 e 1\%) apresentaram maior intensidade e alterações mais definidas quando comparados aos dinamizados, assim como a porcentagem de plantas e folhas que apresentaram sintomas visuais nos tratamentos dinamizados foi menor (Figura 2), e perceptível apenas após a quarta aplicação. Uma substância quando dinamizada em suas diferentes diluições, pode determinar o aparecimento de sintomas mais refinados, isto pode significar que as dinamizações podem ter provocado apenas efeitos fisiológicos não mensuráveis externamente (Fontes, 2005).

A dinamização $12 \mathrm{CH}(0,003 \%$ de álcool) apresentou maior porcentagem de plantas com sintomas de fitotoxidade bem como maior número de folhas afetadas quando comparadas a dinamização $30 \mathrm{CH}$ na mesma graduação alcoólica e $12 \mathrm{CH}(0,7 \%$ de álcool). Resultados semelhantes foram observados por Garbin et al. (2009) em experimentação patogenésica com ácido ascórbico em plantas de feijão. Onde os sintomas visuais no ensaio com a substância dinamizada na $6 \mathrm{CH}$ foram $90 \%$ menos intensos que os observados nas plantas tratadas com dose tóxica do ácido, assim como a porcentagem de plantas e folhas que apresentaram sintomas em cada tratamento também foi menor 80 e $83 \%$ respectivamente.

Os tratamentos aplicados via irrigação não resultaram em alterações foliares observadas pelos mesmos tratamentos quando aplicados via pulverização, foram observados nestes tratamentos alterações apenas nas variáveis biométricas
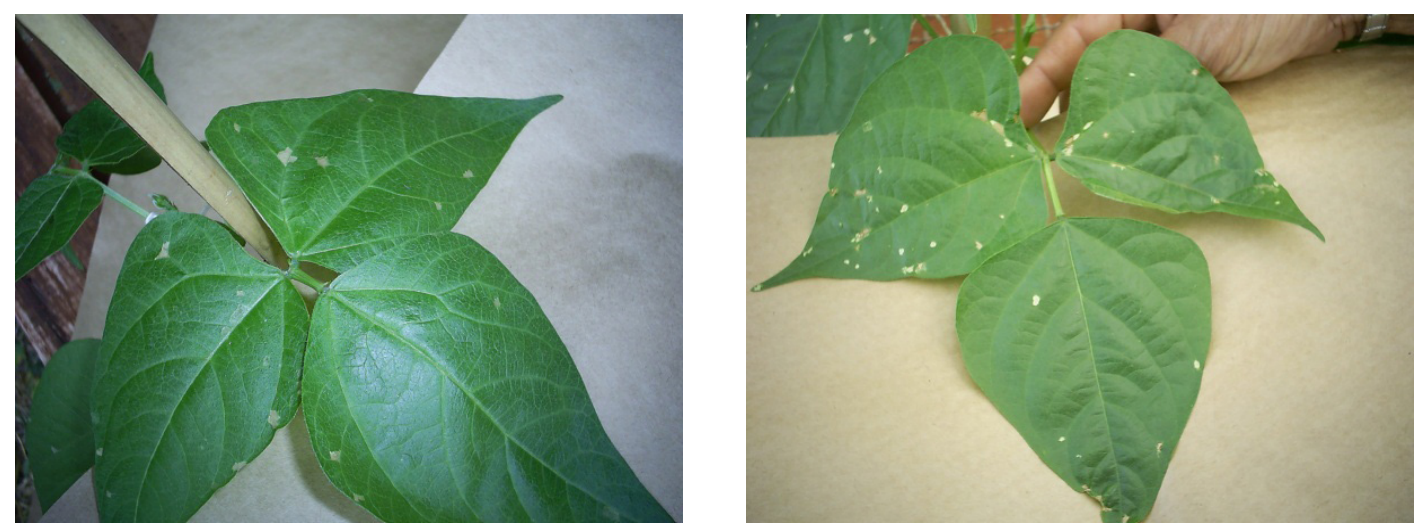

FIGURA 1. Efeito fitotóxico em plantas de feijão provocados pela pulverização de óleo de Eucalyptus citriodora $1 \%$ após 5 aplicações (esquerda) e após 10 aplicações (direita). 
avaliadas. A ausência de sintomas foliares perceptíveis, porém com as variáveis de crescimento alteradas sugere possível efeito fisiológico nas plantas, caracteristica relatada em experimentos homeopáticos (Fontes, 2005). Estes resultados podem ser devido a diluição dos tratamentos pela irrigação. Apesar de controlada o quantidade de água, este processo pode diluir os tratamentos aplicados o que contribui para a suavização dos efeitos esperados.

Pedalino (2006), afirma que diferentes potências atuam de modo diferente, não havendo uma relação lógica entre o aumento da dinamização e o efeito do medicamento, pois diluições diferentes atuam em diferentes locais.

A análise periódica das áreas foliares mostrou que houve efeito significativo na redução no crescimento das folhas para alguns tratamentos (Figuras 3 e 4). Quatro dias após os tratamentos o óleo essencial $0,5 \%, 12 \mathrm{CH}$ e $30 \mathrm{CH}(0,7 \%$ de teor alcoólico) aplicados via pulverização reduziram a área foliar. Sendo mantida a característica inibitória aos oito dias para as dinamizações 12 e $30 \mathrm{CH}(0,7 \%)$, chegando a valores $23 \%$ menores que o controle para a dinamização $30 \mathrm{CH}$. Para o tratamentos aplicados via irrigação, quatro dias após a aplicação foram significativas as diferenças para o dinamizado $12 \mathrm{CH}$ e óleo 0,5 e 1\% comparando ao controle no mesmo dia via irrigação. Após oito dias o óleo na concentração de 1\% reduziu a área em $20 \%$.

Ao final de doze dias os tratamentos pulverizados provocaram redução significativa da área foliar para os tratamentos $12 \mathrm{CH}$ e $30 \mathrm{CH}$ quando comparados ao controle (Tabelas 1 e 2). A altura de planta foi afetada nos tratamentos OE 1\% e $30 \mathrm{CH}(0,007 \%$ de álcool). Para os tratamentos irrigados o OE $1 \%$ e $30 \mathrm{CH}(0,7 \%)$ causaram redução da área e altura de planta revelando o efeito inibidor do desenvolvimento vegetativo do óleo e das homeopatias aplicadas.

Ootani et al. (2010) verificaram o efeito fitotóxico do óleo essencial de E. citriodora sobre

A

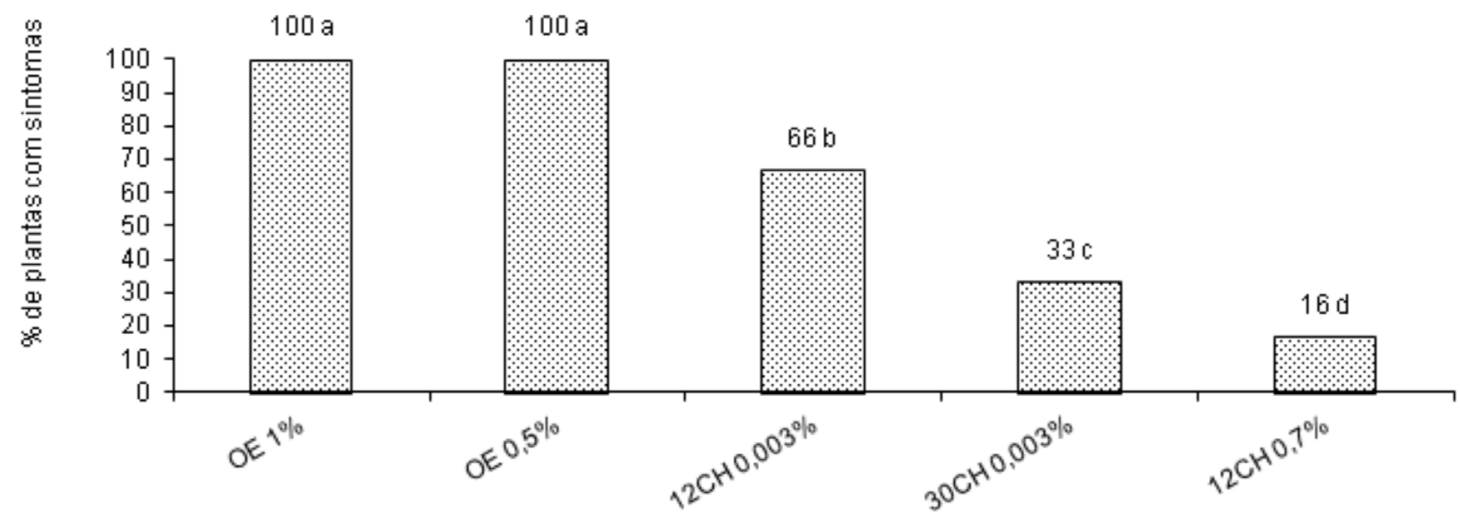

B

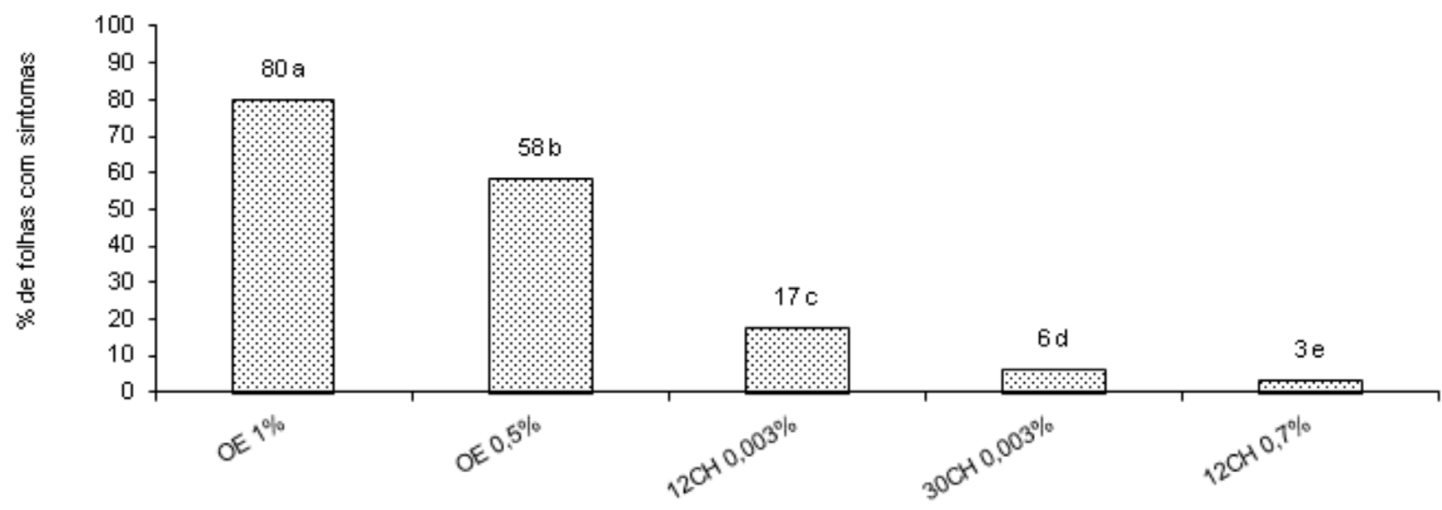

FIGURA 2. Porcentagem de plantas $(A)$ e folhas $(B)$ com sintomas foliares provocados pelo tratamento com óleo essencial e homeopatias de Eucalyptus citriodora tratados via pulverização. Médias seguidas de letras distintas diferem entre si pelo teste de Scott-Knott $p<0,05$. 


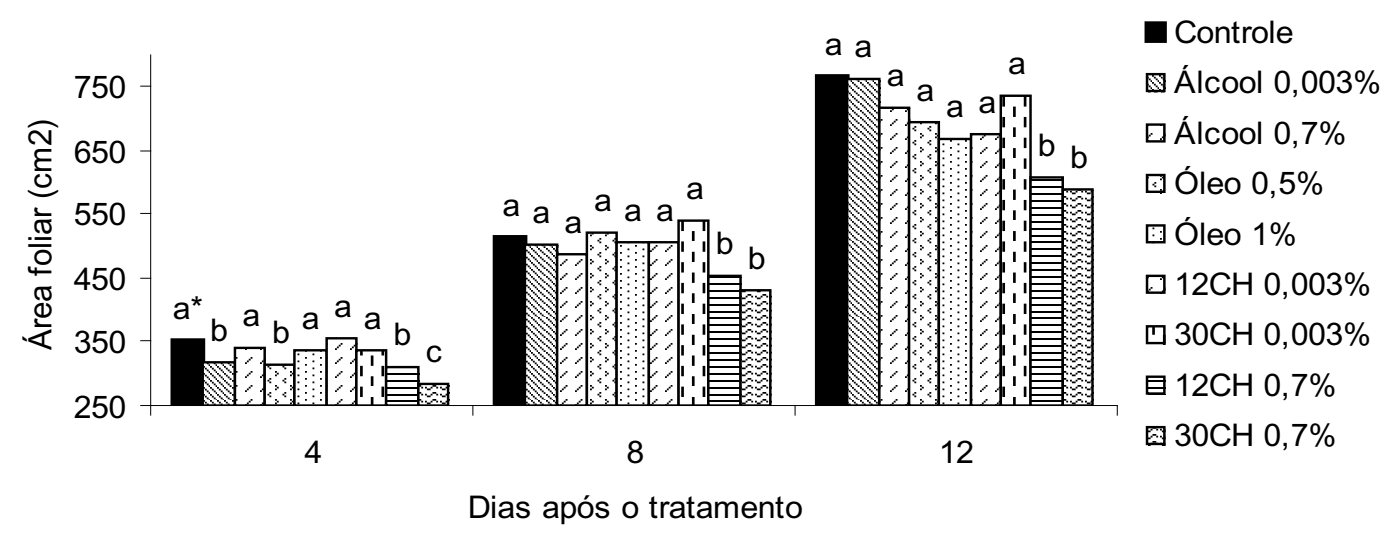

FIGURA 3. Área foliar de plantas de feijão P. vulgaris quatro, oito e doze dias após submetidas a tratamentos com óleo essencial e homeopatia de Eucalyptus citriodora via pulverização. *Médias seguidas de mesma letra não diferem entre si pelo teste de Scott-Knott $p<0,05$.

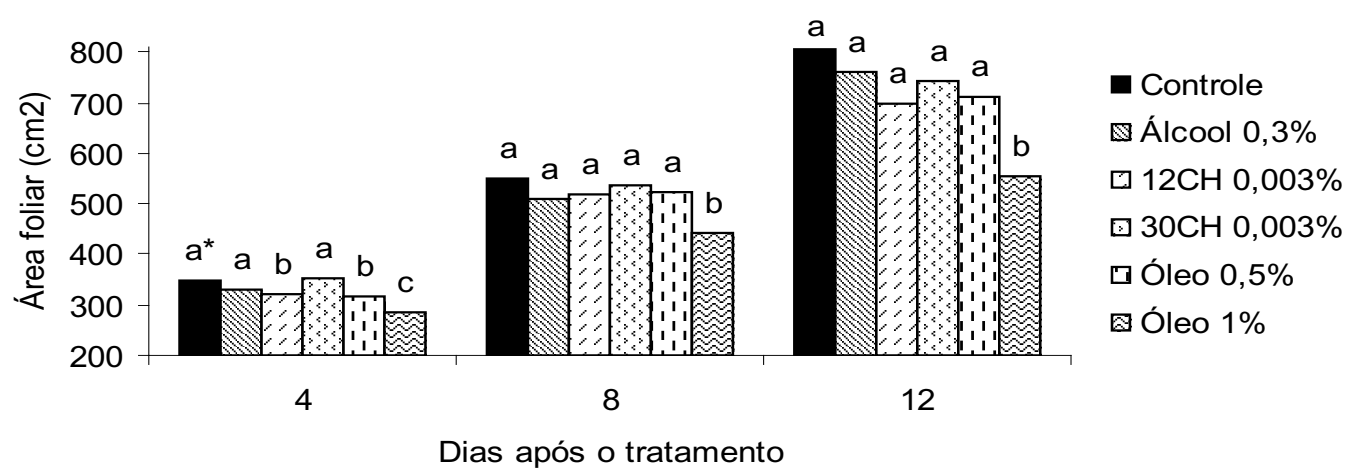

FIGURA 4. Área foliar de plantas de feijão P. vulgaris quatro, oito e doze dias após tratamentos com óleo essencial e homeopatia de Eucalyptus citriodora via irrigação. *Médias seguidas de mesma letra não diferem entre si pelo teste de Scott-Knott $p<0,05$.

TABELA 1. Média para área foliar $\left(\mathrm{cm}^{2}\right)$ e altura de plantas $(\mathrm{cm})$ de feijão (Phaseolus vulgaris) submetidas à experimentação patogenésica com óleo essencial de Eucalyptus citriodora doze dias após o inicio dos tratamentos via pulverização.

\begin{tabular}{ccc}
\hline Tratamentos & Área foliar $\mathrm{cm}^{2}$ & Altura de planta cm \\
\hline Controle & $766,68 \mathrm{a}^{*}$ & $50,12 \mathrm{a}$ \\
Álcool 0,003\% & $762,48 \mathrm{a}$ & $60,84 \mathrm{a}$ \\
Álcool 0,7\% & $716,02 \mathrm{a}$ & $50,46 \mathrm{a}$ \\
OE 0,5\% & $693,06 \mathrm{a}$ & $48,8 \mathrm{a}$ \\
OE 1\% & $669,62 \mathrm{a}$ & $42,06 \mathrm{~b}$ \\
$12 \mathrm{CH} \mathrm{0,003 \%}$ & $676,51 \mathrm{a}$ & $59,04 \mathrm{a}$ \\
$30 \mathrm{CH} \mathrm{0,003 \%}$ & $734,3 \mathrm{a}$ & $55,72 \mathrm{a}$ \\
$12 \mathrm{CH} \mathrm{0,7 \%}$ & $609,3 \mathrm{~b}$ & $52,84 \mathrm{a}$ \\
$30 \mathrm{CH} \mathrm{0,7 \%}$ & $588,28 \mathrm{~b}$ & $36,64 \mathrm{~b}$ \\
\hline $\mathrm{Cv} \%$ & 10,11 & 19,35 \\
\hline
\end{tabular}

*médias indicadas com a mesma letra não diferem entre si pelo teste de Scott-Knott a 5\% de probabilidade 
TABELA 2. Média para área foliar $\left(\mathrm{cm}^{2}\right)$ e altura de plantas $(\mathrm{cm})$ de feijão (Phaseolus vulgaris) submetidas à experimentação patogenésica com óleo essencial de Eucalyptus citriodora doze dias após o inicio dos tratamentos via irrigação.

\begin{tabular}{ccc}
\hline Tratamentos & Área foliar $\mathrm{cm}^{2}$ & Altura de planta/cm \\
\cline { 3 - 3 } Controle & $803,28 \mathrm{a}^{*}$ & $55,7 \mathrm{a}$ \\
Álcool 0,003\% & $760,75 \mathrm{a}$ & $65,9 \mathrm{a}$ \\
OE 0,5\% & $711,29 \mathrm{a}$ & $51,18 \mathrm{a}$ \\
OE 1\% & $556,5 \mathrm{~b}$ & $32,04 \mathrm{~b}$ \\
$12 \mathrm{CH} 0,003 \%$ & $698,85 \mathrm{a}$ & $65,02 \mathrm{a}$ \\
$30 \mathrm{CH} \mathrm{0,003 \%}$ & $742,62 \mathrm{a}$ & $60,34 \mathrm{a}$ \\
\hline $\mathrm{Cv} \%$ & 10,11 & 19,35 \\
\hline
\end{tabular}

${ }^{*}$ médias indicadas com a mesma letra não diferem entre si pelo teste de Scott-Knott a $5 \%$ de probabilidade

o Capim-colchão (D. Horizontalis) 12 horas após a aplicação dos tratamentos. Ressalta-se que os sintomas foram observados pela manifestação de sintomas caracterizados por pontos com aspecto encharcados, sendo características de perda de permeabilidade da membrana, que em seguida tornaram-se cloróticos, aplicação do óleo reduziu o acúmulo de matéria seca da parte aérea e de raízes. Os autores atribuem a alta toxicidade de óleo da espécie E. citriodora a presença de monoterpenos, sendo o citronelal o composto majoritário verificado.

O b-citronelal foi o componente encontrado em maior quantidade $(81.04 \%)$ no cromatograma obtido para o óleo essencial analisado, que pode ser o responsável pelos sintomas fitotóxicos apresentados nas plantas analisadas, assim como no estudo acima citado. Além do citronelal foram encontrados mais 29 compostos diferentes. Os principais componentes do óleo de Eucalipto estão detalhados na Tabela 3. Dentre estas substâncias cita-se o Isopegenol (2,34\%), um dos principais derivados primários do citronelal, e ß-Citronellol (6.05\%) que foi relatado como causador de fitotoxicidez em plantas de amendoinbravo (Euphorbia heterophylla L.) resultando em diminuição no comprimento das partes vegetativas das plantas, resultado semelhante ao encontrado neste trabalho. Estes resultados podem estar associados à inibição da atividade mitótica pelo ß-citronellol (Gusman et al., 1990).

A análise dos sintomas fitotóxicos provocados nas plantas de feijão ao serem comparadas com doenças que afetam a cultura, assemelham-se os provocados pelo fungo Pseudocercospora griseola agente causal da "mancha angular" (Kimati et al., 2005). Para a cura homeopática quando um medicamento que desperta o mesmo padrão de desequilíbrio em plantas sadias (patogenesia) é aplicado em uma planta em desequilíbrio, ela voltaria ao seu equilíbrio anterior, reestabelecendo seu quadro saudável (Bonato, 2007). As semelhanças morfo-anatômicas entre as alterações foliares provocadas pelos tratamentos e as lesões provocadas por $P$. griseola podem ser

TABELA 3. Principais compostos identificados em cromatografia gasosa do óleo essencial de Eucalyptus citriodora Hook (Família Myrtaceae).

\begin{tabular}{ccc}
\hline \multicolumn{3}{c}{ Composição química do óleo essencial de Eucalyptus citriodora } \\
\hline Tempo de retenção (min.) & Substância & Teor (\%) \\
8.042 & a-Pinene & 0.171 \\
9.353 & ß-Terpinene & 0.251 \\
9.443 & ß-Pinene & 0.770 \\
11.355 & Eucalyptol & 2.674 \\
15.475 & Isopulegol & 2.342 \\
16.267 & ß-Citronellal & 81.040 \\
18.492 & ß-Citronellol & 6.058 \\
22.584 & Citronellol acetate & 1.680 \\
& Outros & 5.014 \\
\hline Total & & 100 \\
\hline
\end{tabular}

Rev. Bras. PI. Med., Campinas, v.15, n.4, supl.I, p.734-741, 2013. 
observadas na Figura 5.

Os levantamentos patogenésicos classificam-se de acordo com o tipo de sintomas apresentados, podendo ser consideradas patosenesias morfológicas ou fisiológicas. Avaliando este trabalho, assim como o verificado por Bonato (2007), podem ser classificadas como patogenesias morfo-anatômicas, no qual aplicações de Sulphur na planta medicinal tansagem (Plantago spp) ocasionaram deformações foliares e crescimento em roseta.

Diferente do experimento neste estudo Carvalho (2007) submeteu plantas de Tanacetum parthenium (L.) a soluções homeopáticas de Arnica Montana e verificou redução na porcentagem de partenolídeo, componente de defesa da Artemísia, nas dinamizações $3 \mathrm{CH}$ e $5 \mathrm{CH}$. Resultados como

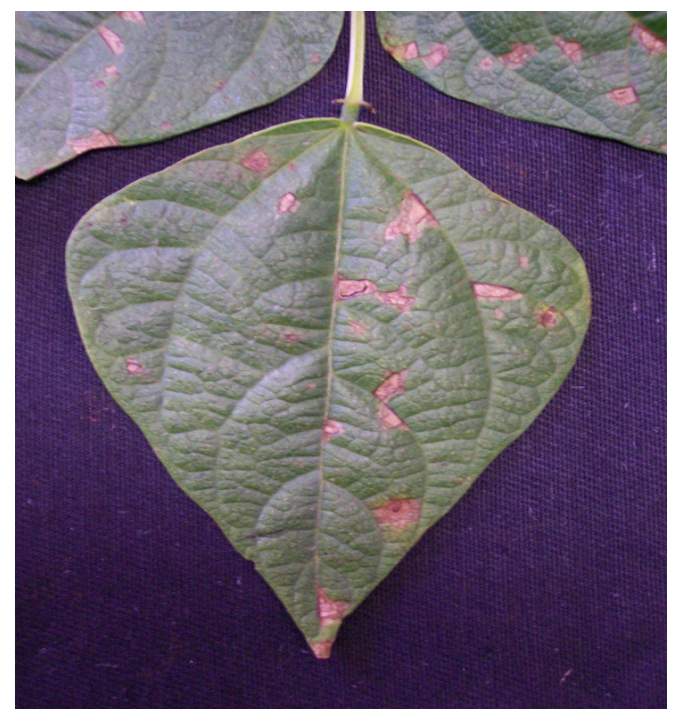

estes evidenciam o potencial de ação de preparados homeopáticos tanto na desenvolvimento morfológico quanto na fisiologia de plantas.

\section{CONCLUSÕES}

O óleo essencial e homeopatias de $E$. citriodora quando aplicado via pulverização provoca no feijoeiro sintomas foliares semelhantes aos provocados por Pseudocercospora griseola. As dinamizações do óleo resultaram em alterações em menor número e menos severas quando comparado as plantas tratadas com óleo em doses não homeopáticas. A semelhança dos sintomas patogenésicos observados levanta a possibilidade do uso de homeopatias do óleo de E. citriodora serem utilizadas de acordo com o princípio homeopático da similitude para o controle da mancha angular.

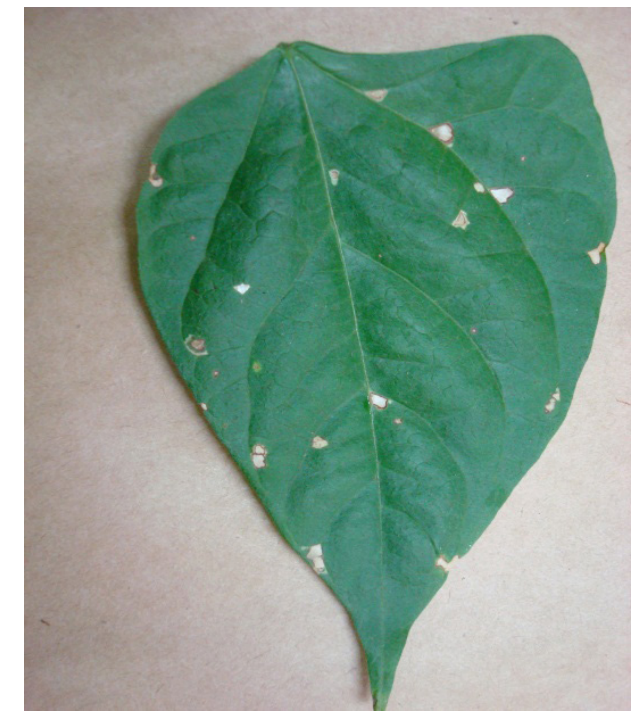

FIGURA 5. Comparação entre folha de feijão afetada por Pseudocercospora griseola (esquerda) e folha de feijão com sintomas patogenésicos de óleo essencial de Eucalyptus citriodora 1\% (direita) após 10 aplicações.

\section{REFERÊNCIA}

BONATO, C.M. Homeopatia em Modelos Vegetais. Cultura Homeopatica. n. 21, p.24-28, 2007.

CARNEIRO, S.M.T.P.G.; AMORIM, L.; BERGAMIN FILHO, A. ; HAU, B.; BIANCHINI, A. . Estimativa da Área Foliar do Feijoeiro Para Quantificação de Danos. In: XXX Congresso Barsileiro de Fitopatologia, 1997. Fitopatologia Brasileira. Brasília. v.22. p. 254-254.

CARNEIRO, S.M.I.P.G. Projeto De Pesquisa Sobre Homeopatia Em Plantas. 2004. 37p. Trabalho de Conclusão de Curso (Especializacao em Homeopatia) Centro de Especialização em Homeopatia de Londrina, Londrina.

CARVALHO, L. M.; CASALI, V. W. D.; LISBOA, S. P.; SOUZA, M. A.; CECON, P. R. A homeopatia Arnica Montana no cultivo de Artemísia. Revista Brasileira de Agroecologia, v.2, n.1, p.1107-1110, 2007.
FERREIRA, D.F. Sisvar versão 4.2. DEX/UFLA, 2003. FHB, Farmacopéia Homeopática Brasileira- Parte I Métodos Gerais. 2 ed. São Paulo: Ed. Atheneu, 1997. FONTES, O.L. Farmácia Homeopática- Teoria e Prática. 2 ed. São Paulo: Ed. Manole, 2005. 388p.

GARBIM, T.H.S.; CARNEIRO, S.M.T.P.G.; ROMANO, E.D.B.; TEIXEIRA, M.Z. Experimentação Patogenética em Feijoeiro para Elaboração de Matéria Vegetal Homeopática. Revista Brasileira De Agroecologia, v.4, n.2, p.1020-1024, 2009.

GUSMAN, A.B.; MUCILLO, G.; PIRES, M.H. Efeito do citronelol sobre a germinação e Desenvolvimento do Amendoim-bravo (Euphorbia heterophyla L.) Semina, v.11, n.1, p.20-24, 1990.

KIMATI, H.; AMORIM, L.; REZENDE, J.A.M.; BERGAMIN FILHO,A.; CAMARGO, L.E.A. Manual De Fitopatologia. 4.ed. São Paulo: Agronômica Ceres. 2005. 663p.

LIPPERT, M. A. M.; BONATO, C.M. Importância dos 
preparados homeopáticos na agricultura e no equilíbrio da biodiversidade. In: I Congresso de Farmácia de Maringá, 2006. Resumos... Maringá: Arquivos Do Mudi, 2007. p.11-11.

OOTANI, M.A.; REIS, M. R.; MACHADO, A.F.L.; AGUIAR, R.W.S.; SANTOS, G.R.; ERASMO, E.A.L. Potencial Alelopático de óleos essenciais de Eucalipto e de Citronela. In: XXVII Congresso Brasileiro da Ciência das Plantas Daninhas, 2010. Resumos... Ribeirão Preto. p.459-463.

NETO, R.M.B. Bases Da Homeopatia. Liga de Homeopatia- Unicamp. 70p., 2006. Disponível em: <http://www.ruymadsen.com.br/basesdahomeopatia. pdf>. Acesso em:10 de jan. 2013.

PEDALINO, C.M.V. Medicamentos homeopáticos em acordes de potência. Cultura Homeopática. n.16, p.18-21, 2006.

ROSSI, F.; ARÉVALO, R.A.; AMBROSANO, E.J.; GUIRADO, N.;AMBROSANO, G.M.B.; MENDES, P.C.D.; MOTA, B.; ATZINGEN, E.M.M.V.; MENUZZO, M.M.; VARELLA, A.S. Aplicação de preparado homeopártico no controle da tiririca em área agroecológica. Revista Brasiveira de Agroecologia. v.2, n.1, p.870-873, 2007.

ZOBY, E. C. Matéria Médica Pura de Hartlaub e Trinks: resgatar ou perder? Cultura Homeopatica. v.2, n.5, p.15-24; 2003. 